\title{
The annotated Vesalius
}

\author{
Vesalius at $\mathbf{5 0 0}$ \\ Thomas Fisher Rare Book Library \\ University of Toronto \\ Toronto, Ont. \\ May 23-Aug. 29, 2014
}

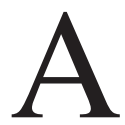

ndreas Vesalius (1514-1564) used dissection and images to revolutionize the way we see the human body and the way we illustrate books. If there is one book from the remarkable time of the medical Renaissance that physicians should know, it is his $D e$ humani corporis fabrica [Structure of the human body] (1543), known as the Fabrica, a magnificent anatomic work.

To celebrate the 500th anniversary of Vesalius' birth, a stunning exhibit at the Thomas Fisher Rare Book Library in Toronto features a copy of his masterpiece, annotated by the author himself. Curated by Philip Oldfield, Vesalius at 500 assembles an unprecedented collection of Vesalius' works and those of his precursors and followers, with intelligent commentary to track his contributions from the perspectives of art, anatomy, medicine and printing.

The Renaissance came late to medicine. In the early 16th century, anatomic knowledge relied on the ancients and was taught by lecturers who did not touch the corpse, leaving dissection to barber assistants. Instead, lecturers read from the second-century Greek physician, Galen, whose works had dominated medicine for 1300 years.

The first few display cases feature works by Galen and Vesalius' predeces-

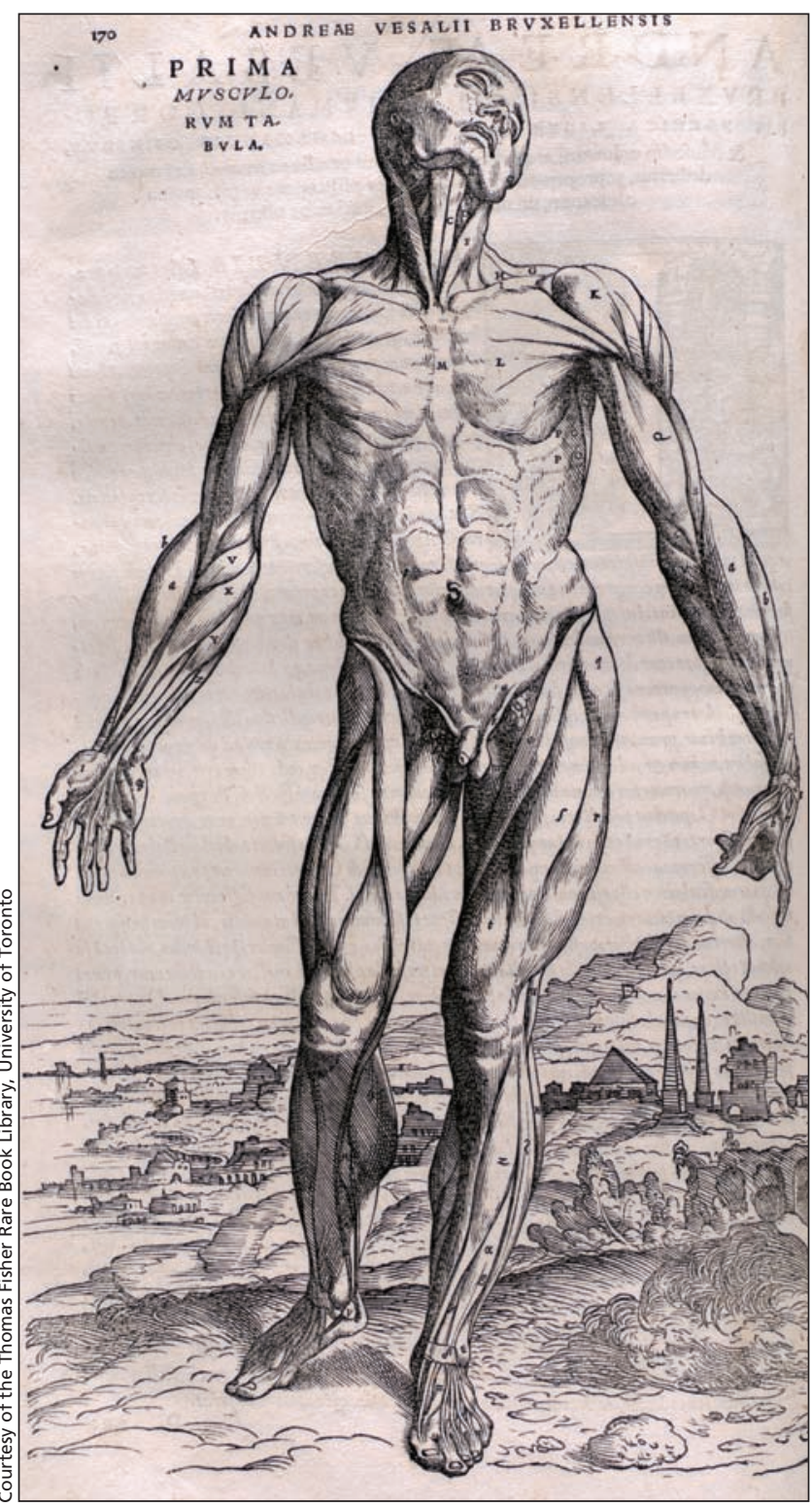

The first of the muscle-men series in Vesalius' Fabrica. His masterpiece changed the way we view the human body. sors and teachers. Small, stylized illustrations of stiff cadavers, helping to expose their own structures, grace occasional pages in these little printed books. Such images were created to help students memorize the names of body parts; they were not designed to contribute information independently of text.
Into the stumbling first steps of this new medium of print and illustration, Vesalius dropped his startlingly innovative and sure-footed creations, all of which are displayed in this exhibit.

Born in Brussels and educated in Paris and Padua, Vesalius became a professor of surgery upon completing his degree in 1537. The following year, he published the slim Tabulae Sex - a folio compendium of anatomic diagrams that relied on his own dissections and the wisdom of Galen. With its original blend of text and image, it was immensely popular, especially with students. The exhibit copy of the Tabulae Sex stands open to the circulatory system showing the rete mirabili, a nonexistent vascular formation in the brain that Galen had imputed to humans on the basis of seeing it in animals. In 1538, Vesalius still followed Galen.

Next appears Vesalius' masterwork, the enormous Fabrica (1543). It presents human anatomy in seven books of multiple illustrations. The frontispiece proclaims the author's anatomic agenda. Vesalius performs his own dissection of a female cadaver. Displaced assistant dissectors squabble on the floor. The animals that once informed Galen's work are thrust to the periphery. The artist - possibly the Flemish Jan Stephan van Calcar — shows himself sketching the scene amid a crowd of onlookers that includes professors and students. Suspended above the cadaver in the place of the professor's lectern is a skeleton: Galen is dead. 
The book sections are each devoted to organ systems - bones, muscles, circulation, nerves, inner organs of digestion and generation. Analogies between male and female, human and animal, together with discussions of the errors of forerunners, conveyed the anatomist's message mostly in Latin, but with Greek and Hebrew, too. Vesalius also explained which tools and methods to use for the best dissections.

The clarity, accuracy and beauty of the illustrations in the Fabrica are striking even today, but especially when compared with their immediate precursors. The elongated bodies, set beside architectural elements or in landscapes with low horizons, suggest that the artist was influenced by a Mannerist, such as Titian in nearby Venice. When reversed and combined, the backgrounds of the "muscle men" images join to form a continuous panorama that moves from lush summer to bleak winter as the cadavers lose their flesh. ${ }^{1}$

Beyond its blend of art and science and its astonishing contributions to anatomy, the Fabrica is a triumph of the technologies of book printing, less than a century after Gutenberg's invention of movable type. The drawings were carved into woodblocks that were transported across the Alps for printing at the workshop of Johannes Oporinus (1507-1568) in Basel. Just as anatomic images were rare in the mid-16th century, European printed book illustration in general was still in its infancy. A favourite early example of the medium is Hartmann Schedel's Nuremberg Chronicle (1493), a book that reuses identical images to depict different towns. A half century later, as distant landscapes were coming into sharper focus on printed pages, Vesalius turned an inquiring eye on the landscape of the human body, increasing the realist detail that viewers could expect from illustration. By insisting that the images be informative in themselves, Vesalius, his publisher and the artists and woodcutters who helped realize his visions were reimagining the possibilities of the new medium, even as they were deepening anatomic knowledge.

In his June 3, 2014, lecture at the Fisher Library, Professor Vivian Nutton explained that the Fabrica was among the most expensive books of the 16th century. An enterprise of debilitating cost to its printer, the project was driven as much by the single-mindedness of its author as by the hunger of its audience. Vesalius not only contributed significant funds to subsidize the printing of the Fabrica, in a run of 600-1000 copies, but he also lent Oporinus vast sums to finance its publication. The publisher died grievously in debt to the anatomist's family.

Though costly, the first edition sold well to professors, wealthy people and libraries. A condensed version, the Epitome, was popular with students and was quickly translated into German. The fame of the Fabrica inspired critics, successors, imitators and even plagiarists, whose works appear in the exhibit's adjacent cases. One of these followers, the surgeon Prospero Borgarucci, attributed his 1568 treatise to Vesalius perhaps to enhance sales - even though the anatomist had died four years earlier. Before his death, Vesalius responded to his critics in essays, which are also on display, and he modified his treatise for a second edition, published in 1555 .

A copy of this second edition, with its numerous marginalia, is the most exciting element of the exhibit. Its owner since 2007, Vancouver pathologist and bibliophile Dr. Gerard Vogrincic conducted a careful investigation that indicated the likely identity of the writer, but he could not decipher the comments. ${ }^{2} \mathrm{He}$ involved Professor Nutton, who confirmed that the notes are written in the hand of Vesalius himself and advised that Vogrincic deposit the book in the Fisher Library. ${ }^{3}$ The "Toronto Vesalius," as Nutton calls it, contains over a thousand of Vesalius' annotations and instructions to his printer in preparation for a third edition. Given that the second edition had not yet sold out - to the great financial distress of its publisher this third edition must have been entirely hypothetical. It was never published.

According to Nutton, most of Vesalius' annotations concern matters of Latin style; however, many indicate his desire to explain to readers the feeling of holding a bone or dissecting a body. Others reveal the extent of his preoccupation with his own masterwork. In a tiny addition, where the anatomist had redrawn a minuscule line on a foot as a necessary correction, Nutton senses the obsession of a passionate man, rereading and revising his work - work that had already changed the world. Nutton described working with the text as one of the great moments of his life.

Vesalius left anatomy behind and engaged in an extensive medical practice in Brussels, eventually serving as physician at the court of Philip II of Spain. He died in 1564 on the return journey from a pilgrimage to Jerusalem. His grave is said to be on the Mediterranean island of Zante (Zakynthos), where, despite the ravages of an 1893 earthquake, investigators still hope to locate his remains.

Most of the Fabrica woodblocks survived into the 20th century and were used to prepare an edition of the illustrations in 1934, but they were destroyed in the 1943 Allied bombing of Munich. The Fabrica itself endures in new formats and old: Norman Publishing and Karger Medical and Scientific Publishers have both published English translations of the book recently, and a census published in 1984 indicated that 154 copies of the first edition then remained in existence. ${ }^{4}$ The Vesalius at 500 exhibit and its handsome, erudite catalogue ${ }^{5}$ perpetuate this half millennium of scholarship and wonder and promise enticing new discoveries in the future.

\section{Jacalyn Duffin MD PhD}

Hannah Chair of the History of Medicine Queen's University

Kingston, Ont.

Jessica Duffin Wolfe MA

English, Book History and Print Culture

University of Toronto

Toronto, Ont.

\section{References}

1. Cavanaugh GST. The panorama of Vesalius: a 'lost' design from the studio of Titian. Athens (GA): Scarum Press; 1996.

2. Vorgrincic G. A clever collector makes an astonishing discovery. Karger: Vesalius at 500. Basel (Switzerland): Karger Medical and Scientific Publishers. Available: www.vesaliusfabrica.com/en/original -fabrica/inside-the-fabrica/vesalius-handwriting.html (accessed 2014 June 8).

3. Nutton V. Vesalius revised: his annotations to the 1555 Fabrica. Med Hist 2012;56:415-43.

4. Horowitz M, Collins J. A census of copies of the first edition of Andreas Vesalius' De humani corporis fabrica (1543), with a note on the recently discovered variant issue. J Hist Med Allied Sci 1984; 39:198-221.

5. Oldfield P. Vesalius at 500. Toronto (ON): University of Toronto; 2014.

CMAJ 2014. DOI:10.1503/cmaj.140738 